\title{
Undisturbed swimming behaviour and nocturnal activity of coral reef fish larvae
}

\author{
Rebecca Fisher $^{1,2, *}$, David R. Bellwood ${ }^{1}$ \\ ${ }^{1}$ Centre for Coral Reef Biodiversity, Department of Marine Biology, James Cook University, Townsville, Queensland 4811, Australia \\ ${ }^{2}$ Present address: National Marine Fisheries Service, Southwest Fisheries Science Center, 110 Shaffer Road, Santa Cruz, \\ California 95060, USA
}

\begin{abstract}
Larval dispersal is shaped by the interaction between oceanographic processes and larval behaviour. To evaluate the potential impact of larval behaviour on this process, we quantified the undisturbed swimming speeds and nocturnal swimming activity of 5 reef fish species throughout their larval phase. We used video techniques to obtain undisturbed observations of swimming behaviour in captive bred larvae. The results conclusively demonstrate that larvae maintain relatively high swimming speeds throughout development. Speeds were consistent among 3 anemonefish species (Amphiprioninae; Amphiprion melanopus, A. percula and Premnas biaculeatus), which swam an average of 3.9 and a maximum of 8.4 body lengths (bl) $\mathrm{s}^{-1}$. However, differences may exist among taxa in the undisturbed swimming speeds of larvae. Highest speeds were recorded in the damselfish Pomacentrus amboinensis (Pomacentridae) and the slowest speeds in the cardinalfish Sphaeramia nematoptera (Apogonidae). The results support short-duration experimental and in situ evidence of high sustained swimming speeds. However, it is striking that larvae routinely swim at such speeds without external stimuli. The proportion of time larvae spent swimming at night increased rapidly towards the end of the larval phase in all 5 species examined. In addition, the undisturbed swimming speeds of larvae were significantly greater at night than during the day. Patterns of nocturnal activity appear to relate to the active nocturnal settlement behaviour of larvae. The pattern of swimming, and speeds achieved, suggest that an active behavioural mechanism for self-recruitment is well within the capabilities of the reef fish larvae examined.
\end{abstract}

KEY WORDS: Reef fish larvae $\cdot$ Larval behaviour $\cdot$ Swimming activity Resale or republication not permitted without written consent of the publisher

\section{INTRODUCTION}

Patterns of dispersal during the larval phase have important implications for many marine organisms, affecting the degree of genetic connectivity (Doherty et al. 1995), levels of self-recruitment (Cowen et al. 2000), and adult population dynamics (Doherty \& Williams 1988). Knowledge of the extent of larval dispersal among reefs is essential for designing zoning plans and for successful fisheries management (Shanks et al. 2003). Although it is clear that ocean currents influence the dispersal of marine larvae, the extent to which larval behaviour may override their effect is a matter of considerable debate (Roberts 1997, 1998, Bellwood et al. 1998, Cowen et al. 2000). It is likely that the overall dispersal patterns of larvae are a result of the interaction between prevailing oceanographic processes and larval biology (cf. Cowen 2002). Two mechanisms that can be employed by marine organisms to actively influence their dispersal are directed swimming behaviour and vertical migration. A recent review by Sponaugle et al. (2002) clearly identified the potential impact of such behaviour on the degree of self-recruitment in marine populations. The extent to which active self-recruitment behaviour may occur is critically dependent on the behavioural and sensory capabilities of larvae, as well as the rate at which these abilities develop during their pelagic phase.

In tropical reef fish larvae, the potential effects of active swimming behaviour have recently received considerable attention, with the discovery that larvae are able to achieve high swimming speeds and en- 
durance both at settlement and during development (Fisher et al. 2000, reviewed in Leis \& McCormick 2002). Data from these studies have been incorporated into models, which document the potential impact of active behaviour on larval dispersal patterns (e.g. Armsworth 2001, Armsworth et al. 2001). However, much of this work on swimming abilities has been based on maximal performance measures such as U-crit (maximum sustainable swimming speed) and sustained swimming trials, both of which are measured in current flumes (e.g. Stobutzki \& Bellwood 1997, Fisher et al. 2000). These flume-based studies provide an upper limit to the potential effect that larvae may have on dispersal through active swimming, and suggest that reef fish larvae can maintain high speeds for considerable lengths of time (Fisher \& Bellwood 2001, 2002).

An alternative approach has been to follow latestage larvae directly in the field (Leis \& Carson-Ewart 1997, Trnski 2002, Hindell et al. 2003). This method has the advantage that larvae are able to 'choose' their swimming speed, although the extent to which the observer changes the 'normal' behavioural patterns and swimming speeds of the larvae is unknown. Furthermore, all such in situ observations have been restricted to late-stage pelagic larvae that are generally considered ready to settle on the reef. No in situ swimming speeds are currently available for younger larvae. It is during the prolonged larval stage that active swimming is likely to have the greatest impact on their dispersal. The question remains, however: at what speed do larvae choose to swim when undisturbed in nature? An answer to this question is critical if we are to fully understand the extent to which larval behaviour may influence dispersal patterns or provide a mechanism for active self-recruitment. Information on the undisturbed swimming behaviour of larvae at hatching and throughout their larval phase is crucial to our understanding of the impact that larval behaviour may have on dispersal, particularly when considering behavioural mechanisms for active self-recruitment.

Central to the question of active behaviour and control of dispersal is the issue of nocturnal as opposed to diurnal behaviour. All work on the swimming capabilities of larvae has been conducted during the day, or under conditions of constant light (e.g. Leis \& CarsonEwart 1997, Stobutzki \& Bellwood 1997). Settlement by many reef fish larvae occurs at night (Dufour \& Galzin 1993, Holbrook \& Schmitt 1997). It therefore appears that reef fish larvae do actively swim at night, at least in the later part of their larval phase. However, no studies have examined changes in the nocturnal swimming behaviour of larvae throughout development.

One way of studying swimming speeds and activity of larvae is by filming undisturbed larvae in rearing aquaria. This has been successfully undertaken with temperate (Hunter 1972, Hunter \& Kimbrell 1980) and subtropical species (Fuiman et al. 1999), and may be readily applied to the larvae of tropical reef fishes. The advantage of this method is that activity levels, behavioural patterns and swimming speeds of larvae can be quantified throughout the larval period, with no disturbance to the larvae. In addition, infrared filming techniques allow behaviour to be examined during the day and night. Using these techniques, we present the first evaluation of the undisturbed swimming speeds and nocturnal swimming activity of reef fish larvae throughout their larval phase. This permits a direct evaluation of the potential for these larvae to actively facilitate self-recruitment via swimming behaviour.

\section{MATERIALS AND METHODS}

Larval rearing. Larvae were reared in a closed saltwater aquarium system at the James Cook University Research Aquarium Facility. Adult brood stock were kept in $>1000 \mathrm{l}$ aquaria and were fed a diet of chopped pilchards, prawns and the sergestid Ascetes twice per day. For the demersal spawning species (Amphiprion melanopus, A. percula, Premnas biaculeatus, Pomacentrus amboinensis), eggs were laid on artificial substrata and were transported to rearing tanks prior to hatching. Eggs from the mouth-brooding species (Sphaeramia nematoptera) were obtained directly from brooding adults. Larvae were reared in a light and temperature controlled room in $104 \mathrm{l}$ aquaria covered externally by black opaque plastic. Larval densities ranged from approx. 1 fish $\mathrm{cm}^{-3}$ at hatching to $1 \mathrm{dm}^{-3}$ at settlement. Water temperature was maintained at 27.5 to $29^{\circ} \mathrm{C}$ using $2 \times 100 \mathrm{~W}$ submersible aquarium heaters. Larvae were fed $>52 \mu \mathrm{m}$ filtered, wild caught plankton, supplemented occasionally by rotifers and Artemia, at prey densities of 3 to 6 ind. $\mathrm{ml}^{-1}$. Food was added to the rearing tanks as soon as the lights were turned on each day. Nannochloropsis sp. algae were used to green the water during the day, and the tanks were flushed slowly with fresh seawater at night (at a rate of $0.151 \mathrm{~min}^{-1}$ ). Flushing was controlled by a solenoid that automatically turned the water flow on at the same time the lights were turned off each night. The addition of green culture to rearing tanks provides a gradual light gradient, allowing the larvae to 'choose' their preferred light intensity by adjusting their depth. A 13:11 h day:night photoperiod was used for all larval rearing. Each rearing tank was illuminated during the day using $4 \times 36 \mathrm{~W}$ 'daylight' fluorescent tubes. These globes provide a light spectrum that is comparable to that of natural daylight (Job $\&$ Bellwood 2000). A single $8 \mathrm{~W}$ fluorescent 'daylight' 
globe was used to illuminate both tanks at night. This was covered in several layers of neutral density filter material so that the light output at the tank surface was equivalent to levels of a half-moon intensity at night. The size and growth rates of larvae reared using this protocol closely resemble those of larvae in the field (Job \& Bellwood 2000).

Three clutches were raised from each of 3 anemonefish species (Amphiprioninae; Pomacentridae): Amphiprion melanopus, A. percula and Premnas biaculeatus. In addition, a single clutch of Pomacentrus amboinensis (Pomacentrinae; Pomacentridae) and Sphaeramia nematoptera (Apogonidae) were raised. All 5 of these species were filmed throughout their larval phase at regular intervals (Table 1 ).

Filming, video analysis and data extraction. Larvae were filmed using an infrared-sensitive black and white camera. This was centrally mounted $30 \mathrm{~cm}$ above the surface of the rearing tank. The field of view ranged from 11.4 to $65.3 \mathrm{~cm}^{2}$ at the surface, which is equivalent to a minimum of $0.3 \%$ and a maximum of $1.8 \%$ of the surface area of the rearing tank. Both the filming area and the surface area of the tank represent quite large areas relative to the size of the fish throughout their development. The largest larvae account for only $0.24 \%$ of the filming area and $0.004 \%$ of the surface area of the rearing tank. Given these dimensions, it is unlikely that larval swimming behaviour would be influenced by edge effects of the rearing tank. Larvae were not observed to associate with the walls of the tank until after settlement. In addition, data were only obtained from footage of larvae that did not interact with other larvae during their time in the field of view.

For filming at night, the rearing tank was illuminated using a $14 \mathrm{~W}$ infrared light (output range $>800 \mathrm{~nm}$ ) (cf. Batty 1987). Adult marine fishes are insensitive to wavelengths greater than $750 \mathrm{~nm}$ (Levine \& MacNichol 1982), and it appears that reef fish larvae are also insensitive to infrared light throughout development (Job \& Shand 2001). Larvae were filmed twice during the day ( 1 to $3 \mathrm{~h}$ after 'lights-on' and 1 to $3 \mathrm{~h}$ before 'lights-off') and twice during the night (1 to $2 \mathrm{~h}$ after 'lights-off' and 1 to $2 \mathrm{~h}$ before 'lights-on'), with each filming period lasting 10 to $15 \mathrm{~min}$. Pilot-study data revealed no changes in larval behaviour during the day or night (examined once every $2 \mathrm{~h}$ ). Two time slots during the day and 2 at night were subsequently analysed. The camera was linked to a VHS VCR, which was programmed to record during the selected filming times. Ten minutes prior to filming, a timer was used to turn off the aeration and heaters in the larval rearing tanks. At night a solenoid was used to turn off the water flow during filming (water flow was turned off during the day at all times because of the use of green-water culture techniques). Nighttime water flow rates were very slow $\left(0.15 \mathrm{l} \mathrm{min}^{-1}\right)$, and so most circulation in the tanks was due to gentle aeration. During pilot studies, no changes in the behaviour of larvae were observed when aeration and water flow were turned off, other than a loss of rheotaxis in the absence of current flow. As the filming process was automated, no human activity was necessary and filming could be conducted under completely undisturbed conditions. A black cloth curtain surrounding the entire rearing area ensured minimal disturbance at other times.

Recorded VHS video was captured and converted to mpeg format digital video files. Video was captured at a frame rate of $30 \mathrm{~s}^{-1}$, providing a temporal resolution of $0.033 \mathrm{~s}$. Captured video files were $320 \times 240$ pixels, and the larvae ranged in size from 8 to 51 pixels in length. Every filming slot $\left(4 \mathrm{~d}^{-1}\right)$ was saved as a separate video file and from each a minimum of 10 individual fish were tracked using the tracking program 'Vedda' (by R. Beare, CSIRO Mathematical and Information Sciences, Sydney). This program records the position, area, shape and orientation of the fish in every frame $(1 / 25$ th of a second). The position of larvae is given as a series of $x, y$ co-ordinates, expressed in pixels across the field of view. These $x, y$ co-ordinates were converted to instantaneous distance in pixels, calculated using Pythagoras' theorem and averaged over 2 frames to smooth tracking inconsistency caused by image noise (a 2-point moving average). The maximum and average undisturbed speed measurements for each individual fish from each video file were

Table 1. Study species used for undisturbed swimming experiments

\begin{tabular}{|lcccccc|}
\hline Species & $\begin{array}{c}\text { Age of larvae } \\
\text { (d since } \\
\text { hatching) }\end{array}$ & $\begin{array}{c}\text { Number of } \\
\text { clutches }\end{array}$ & $\begin{array}{c}\text { Larval } \\
\text { duration } \\
\text { (d) }\end{array}$ & $\begin{array}{c}\text { Egg } \\
\text { duration } \\
\text { (d) }\end{array}$ & $\begin{array}{c}\text { Mean total } \\
\text { length } \\
\text { (hatching) }\end{array}$ & $\begin{array}{c}\text { Mean total } \\
\text { length } \\
\text { (settlement) }\end{array}$ \\
\hline Amphiprion melanopus & $1,3,5,7,9$ & 3 & $8-9$ & $7-8$ & 4.5 & 7.9 \\
Amphiprion percula & $1,3,5,7,9$ & 3 & $8-9$ & $7-8$ & 3.6 & 7.2 \\
Premnas biaculeatus & $1,3,5,7,9$ & 3 & $8-9$ & $7-8$ & 3.9 & 8.7 \\
Pomacentrus amboinensis & $2,6,9,12,15,18,21$ & 1 & $20-21$ & $3-4$ & 2.6 & 13.3 \\
Sphaeramia nematoptera & $4,7,11,18,22,26$ & 1 & $24-26$ & $6-7$ & 3.5 & 11.5 \\
\hline
\end{tabular}


obtained. Speeds were converted to body lengths per second ( $\mathrm{bl} \mathrm{s} \mathrm{s}^{-1}$ ) based on the size of 10 larvae (in pixels) from each video file from which speed measurements were obtained. Because of the green-water culture technique and the type of lens used, the focal depth into the rearing tank was relatively narrow (max depth range $<3 \mathrm{~cm}$ ). The calculated error in swimming speed measurements due to varying depth of the larvae was less than $6.5 \%$. For night video files the number of frames (time) larvae spent either in 'active' or 'inactive' swimming behaviour was manually recorded. Active behaviour was identified by a horizontal orientation (inactive fish tend to 'hang' at a $45^{\circ}$ angle in the water column), and the obvious movement of caudal or pectoral fins. All daytime fish showed 'active' behaviour. Data were expressed as the percentage of time that observed larvae spent in active behaviour at night. These data extraction procedures resulted in 2 data sets: (1) the average and maximum undisturbed swimming speed of each larva, and (2) the time spent in active behaviour at night.

Data analysis. Paired $t$-tests were used to compare undisturbed swimming speeds between the 2 filming times during the day and \% time spent in active behaviour for the 2 filming times at night, for all days that larvae were filmed. No significant difference was found between early ( 1 to $3 \mathrm{~h}$ after lights on for daytime measurements and 1 to $2 \mathrm{~h}$ after lights off for nighttime measurements) and late (1 to $3 \mathrm{~h}$ before lights off for daytime measurements and 1 to $2 \mathrm{~h}$ before lights on for nighttime measurements) filming times (Table 2). Thereafter, all analysis were performed on the pooled observations from both time slots. Daytime swimming data and \% time larvae spent active at night at each age were available from 3 separate clutches for each age for the 3 anemonefish species, but only a single clutch was available for Pomacentrus amboinensis and Sphaeramia nematoptera. These last 2 species were not included in statistical analyses, but were included in graphical comparisons. All analyses were performed using the means of 3 clutches of anemonefish at each age.

A 2-way MANOVA, with species and age as fixed factors, was used to compare the average and maximum daytime swimming speeds of larvae, and time spent active at night, for the 3 anemonefish species throughout development. Statistical analyses were performed using SPSS, and assumptions were examined using residual plots. The percentage of time larvae spent active at night was square-root transformed to meet the assumptions of the analysis. The squareroot transformation was favoured over the typical arcsine transformation because it provided greater homogeneity of variance.

As no significant effect was found due to age in either the average or maximum relative undisturbed swimming speed $\left(\mathrm{bl} \mathrm{s}^{-1}\right)$ of the 3 anemonefish larvae throughout development (Table 3), the undisturbed swimming speeds of these 3 species were compared to the 2 other species (Pomacentrus amboinensis and Sphaeramia nematoptera) by averaging across all ages. The percentage of time all 5 species spent in active behaviour at night was compared throughout development based on developmental age, where age (measured from fertilisation) is expressed as a proportion of duration of the larval period (time to metamorphosis measured from fertilisation). This measure of ontogenetic development was used in preference to a similar measure based on length (Fuiman et al. 1998) because it describes a greater amount of the variation

Table 3. Amphiprion melanopus, A. percula and Premnas biaculeatus. Two-way MANOVA of average and maximum daytime undisturbed swimming speed and time larvae spend active at night. Species and age were entered as fixed factors and the analysis is based on clutch means at each age $(n=3)$. Only anemonefish species are included. Between-subject effects are only shown for significant multivariate tests

\begin{tabular}{|lccr|}
\hline Multivariate tests (Pillai's trace) & $F$ & $\mathrm{df}$ & \multicolumn{1}{c|}{$\mathrm{p}$} \\
\hline Species & 1.94 & 6,52 & 0.092 \\
Age & 3.39 & 12,81 & $<0.001$ \\
Species $\times$ Age & 1.63 & 24,81 & 0.054 \\
Between-subject effects (Age) & & & \\
Average speed & 0.87 & 8,27 & 0.493 \\
Maximum speed & 1.93 & 8,27 & 0.134 \\
Time spent active at night (\%) & 21.95 & 8,27 & $<0.001$ \\
\hline
\end{tabular}


among species in the ontogeny of swimming abilities (Fisher et al. 2000) and visual abilities (Job \& Bellwood $2000)$ in these larvae. In addition, developmental age provides a unit of ontogenetic measurement that is directly related to the length of pelagic duration of these larvae, and is most relevant when considering how the behaviour of larvae may influence dispersal.

The average and maximum undisturbed swimming speed of larvae in body lengths per second $\left(\mathrm{bl} \mathrm{s}^{-1}\right)$ were converted to undisturbed swimming speeds in $\mathrm{cm} \mathrm{s}^{-1}$ using mean total lengths for each species at each age. Length data for Amphiprion melanopus, Pomacentrus amboinensis and Sphaeramia nematoptera were obtained from Fisher et al. (2000) and for Amphiprion percula and Premnas biaculeatus from direct measurements of reared larvae. Length data for all species were obtained from multiple batches of larvae reared using the identical protocol in the same facility. Using length measurements from different batches of larvae introduces some additional error, and does not allow us to compare among-clutch variation in swimming performance within species. However, it provides a robust estimate of the speeds of larvae in $\mathrm{cm} \mathrm{s}^{-1}$, units that are directly comparable to currents and other hydrological features.

Changes in average and maximum undisturbed swimming speeds were examined throughout ontogeny for the 5 study species, using scatter plots, regression and ANOVA of regression. Average and maximum undisturbed swimming speeds expressed in $\mathrm{cm} \mathrm{s}^{-1}$ were then compared with U-crit estimates of swimming speed for each of the species for which U-crit data are available in Fisher et al. (2000), using linear regression. An ANOVA of regression was used to test the significance of this relationship, and 95\% confidence limits used to determine whether the slope of this relationship was significantly different from 0.5 (this represents $50 \%$ of U-crit, which is the estimated swimming speed that larvae should be able to maintain for significant lengths of time; Fisher \& Bellwood 2002).

As larvae only show active nocturnal swimming behaviour near settlement, nighttime undisturbed swimming-speed data were obtained for the last 2 experimental ages, 7 and $9 \mathrm{~d}$ after hatching (data were obtained from 2 clutches of Amphiprion melanopus and 1 clutch of Premnas biaculeatus). Because these species settle at around 8 to $9 \mathrm{~d}$ after hatching, these days are around settlement for these species. The average and maximum undisturbed swimming speeds both day and night (converted to $\mathrm{cm} \mathrm{s}^{-1}$ based on length data) were compared between these 2 ages, based on the means of the 3 clutches using a 2-way factorial MANOVA, with age and day/night as fixed factors. This analysis was performed using SPSS, and assumptions were tested using residual plots.

\section{RESULTS}

\section{Undisturbed swimming speeds (bl s$\left.~^{-1}\right)$}

No significant difference was found in the average or maximum undisturbed swimming speeds of larvae early in the day or late in the day (Table 2). In addition, the average and maximum undisturbed swimming speeds of the anemonefish larvae were both relatively consistent among the 3 species examined, as well as throughout development. MANOVA revealed no significant difference in either the average or maximum undisturbed swimming speeds (expressed in $\mathrm{bl} \mathrm{s}^{-1}$ ) among species or across ages, although a significant effect of age was found for the percentage of time larvae spent actively swimming at night (Table 3 ). Anemonefish larvae swam at an average speed of $3.9 \mathrm{bl} \mathrm{s}^{-1}$ throughout development, and their maximum undisturbed swimming speed was $8.4 \mathrm{bl} \mathrm{s}^{-1}$. A comparison of the average and maximum undisturbed swimming speeds of all 5 species (averaged across age) suggests that there are differences in the undisturbed swimming speeds of larvae at higher taxonomic levels. The undisturbed swimming speeds of Sphaeramia nematoptera larvae were slower than all the pomacentrid species examined (Fig. 1). Of these, Pomacentrus amboinensis larvae swam at the highest speeds (Fig. 1).

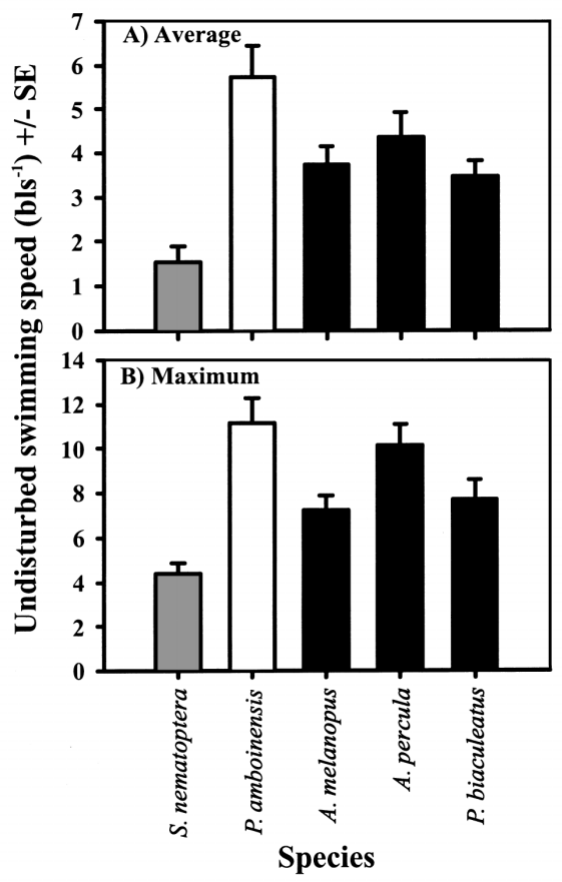

Fig. 1. (A) Average and (B) maximum undisturbed daytime swimming speeds for all 5 study species averaged across age ( $\mathrm{n}=5$, except for Sphaeramia nematoptera, for which $\mathrm{n}=4$ ). Amphiprioninae-Amphiprion melanopus, A. percula and Premnas biaculeatus, solid bars; S. nematoptera, grey bar; Pomacentrus amboinensis, open bar 


\section{Undisturbed swimming speeds $\left(\mathrm{cm} \mathrm{s}^{-1}\right)$}

Average undisturbed swimming speeds in $\mathrm{cm} \mathrm{s}^{-1}$ for all species were comparable at hatching, ranging from 1.0 to $1.7 \mathrm{~cm} \mathrm{~s}^{-1}$ (Fig. 2). However, the developmental rate of undisturbed swimming speed in $\mathrm{cm} \mathrm{s}^{-1}$ differed among the 3 groups of taxa examined (Fig. 2). Undisturbed swimming speed in $\mathrm{cm} \mathrm{s}^{-1}$ increased significantly for Pomacentrus amboinensis throughout development, which showed a strong increase in average, as well as maximum, undisturbed swimming speed with age (Fig. 2, Table 4). P. amboinensis were the fastest larvae at settlement (average $7.6 \mathrm{~cm} \mathrm{~s}^{-1}$, maximum $14.9 \mathrm{~cm} \mathrm{~s}^{-1}$ ). Undisturbed swimming speed in $\mathrm{cm}$ $\mathrm{s}^{-1}$ also increased significantly throughout development for the Amphiprionine larvae, although only for maximum undisturbed swimming speed (Fig. 2, Table 4). Average undisturbed swimming speed in $\mathrm{cm} \mathrm{s}^{-1}$ did not increase significantly during ontogeny for these larvae (Fig. 2, Table 4). However, this differ-

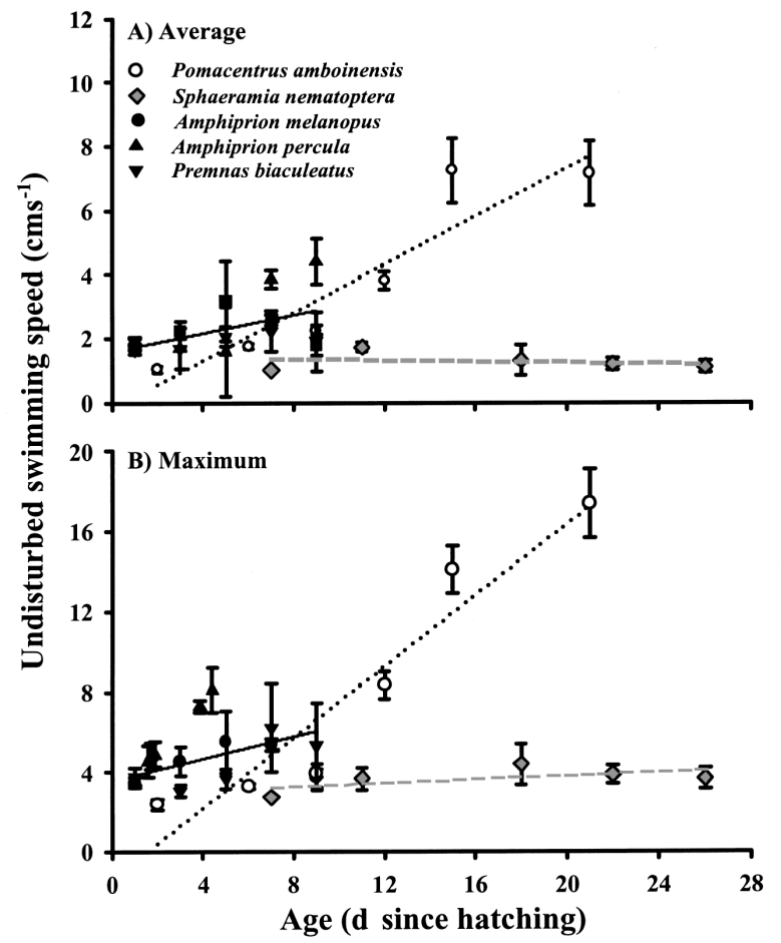

Fig. 2. Relationship between (A) average and (B) maximum undisturbed daytime swimming speeds in $\mathrm{cm} \mathrm{s}^{-1}$ for all 5 species and age. Solid line indicates the fitted regression for the Amphiprioninae (A. melanopus, Amphiprion percula and Premnas biaculeatus); dotted line Pomacentrus amboinensis and the grey dashed line Sphaeramia nematoptera. Regression statistics are summarized in Table 4 ence is probably due to the smaller size at settlement of anemonefish larvae compared to $P$. amboinensis (Table 1); their speed in bl s${ }^{-1}$ is similar (Fig. 1). Neither average nor maximum undisturbed swimming speed increased throughout development for the Sphaeramia nematoptera larvae, which swam at consistently slow speeds (Fig. 2, Table 4).

There was a significant relationship between undisturbed swimming speed and U-crit for both average $\left(F_{1,15}=22.67, \mathrm{p}<0.001, \mathrm{r}^{2}=0.62\right)$ and maximum $\left(F_{1,15}=\right.$ $\left.26.45, \mathrm{p}<0.001, \mathrm{r}^{2}=0.65\right)$ undisturbed swimming speed (Fig. 3). The slope of this relationship was significantly less than 0.5 for average undisturbed swimming speed. On average, larvae swam at $19 \%$ of their U-crit speed (Fig. 3). The maximum undisturbed swimming speed of larvae, however, was not significantly different from $50 \%$ U-crit, based on $95 \%$ confidence limits around the slope coefficient obtained from regression $(0.43 \pm 0.18)$, suggesting that these swimming speeds increase in proportion to $50 \%$ of their U-crit during development. It is clear that this relationship holds extremely well for young larvae of all species, with all values falling within the $95 \%$ confidence limits. However, as the larvae get older, the variation among species increases considerably (Fig. 3). When $F$-ratios were used to determine whether there was a significant difference between a regression fitted to all species together (as shown on Fig. 3) and regressions fitted individually to each species, both average and maximum undisturbed swimming speed differed significantly $\left(F_{10,14}=5.26, \mathrm{p}=0.006\right.$ and $F_{10,14}=9.11$, $\mathrm{p}=0.0006$, respectively) suggesting that the relationship between undisturbed speed and U-crit is not similar among all species. However, if only younger stage larvae were included (i.e. excluding the last 2 ages before settlement for each species), then there was no significant difference $\left(F_{4,8}=4.02, \mathrm{p}=0.10\right.$, $F_{4,8}=3.44, \mathrm{p}=0.12$, respectively), suggesting that these differences were largely due to increasing variation among the species nearing settlement. 


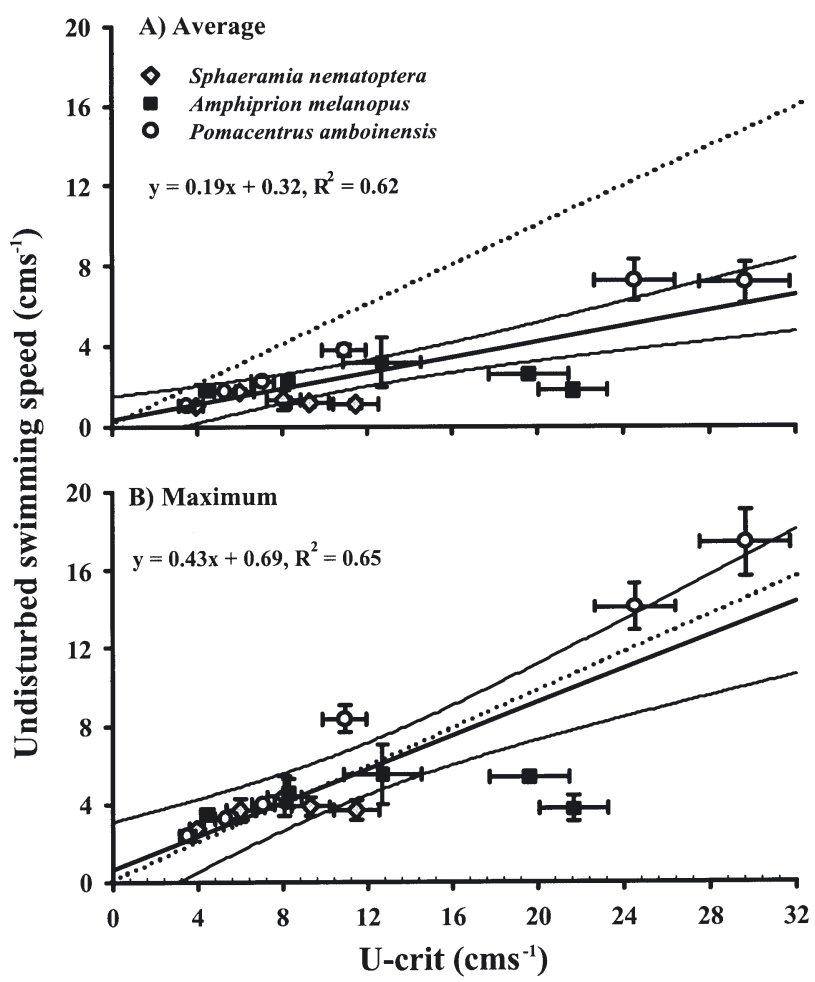

Fig. 3. Amphiprion melanopus, Pomacentrus amboinensis and Sphaeramia nematoptera. Relationship between (A) average and (B) maximum undisturbed daytime swimming speeds in $\mathrm{cm} \mathrm{s}^{-1}$ of $A$. melanopus, $P$. amboinensis and $S$. nematoptera and U-crit (maximum sustainable swimming speed; Fisher \& Bellwood 2002). Dotted line indicates an undisturbed swimming speed of $50 \%$ of U-crit; solid black line indicates fitted regression $\pm 95 \%$ confidence limits based on all 3 species. Equations are for fitted regression, including $\mathrm{r}^{2}$ values. U-crit values were obtained from Fisher et al. (2000)

\section{Nocturnal activity of reef fish larvae}

Paired $t$-tests indicated no significant difference in the percentage of time larvae spend in active behaviour at night between the early and late filming times (Table 2). The percentage of time anemonefish larvae spend actively swimming at night significantly increased throughout development, but was consistent among species (Fig. 4). MANOVA indicated a significant effect of age, but no significant difference among the 3 species (Table 3). Post-hoc tests show a significant increase in the time larvae spent active at night between 3 and $5 \mathrm{~d}$ after hatching, and then another significant increase between 5 and $7 \mathrm{~d}$ after hatching (Fig. 4A). Anemonefish larvae begin to spend $>50 \%$ of their time active at night from around $7 \mathrm{~d}$ after hatching, which is 1 or $2 \mathrm{~d}$ before settlement in these species. This developmental pattern of nocturnal activity is consistent with the single clutch of Pomacentrus amboinensis larvae, which also showed significant levels

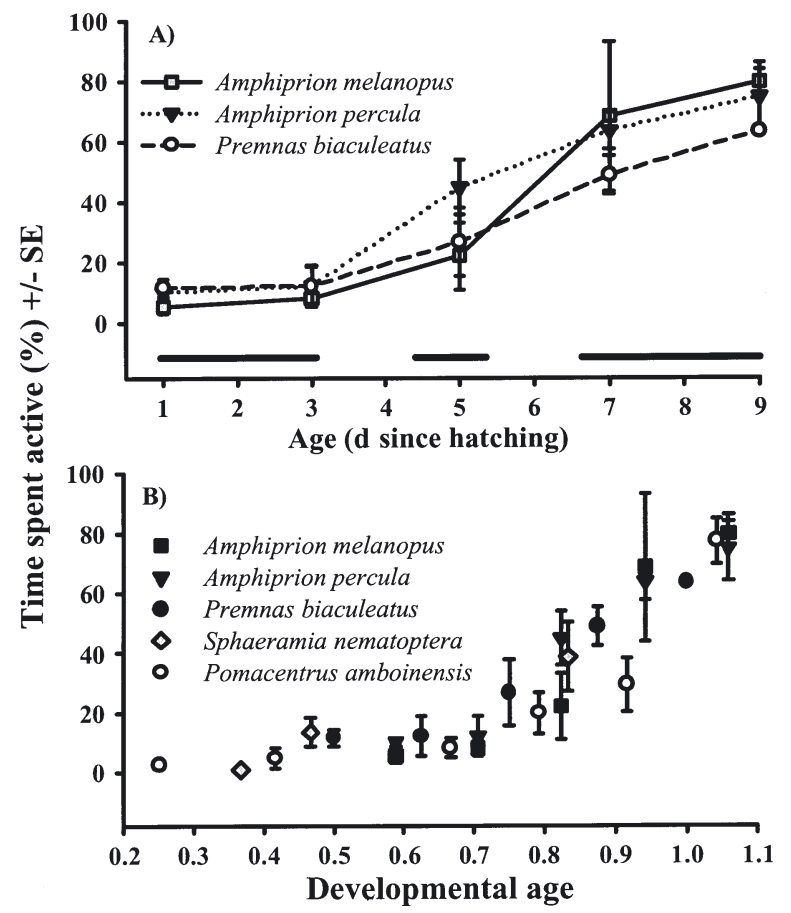

Fig. 4. Percentage of time larvae spend in 'active' behaviour at night. (A) Mean at each age (expressed in days since hatching) for 3 species of anemonefish (Amphiprion melanopus, A. percula and Premnas biaculeatus). Thick lines along the $X$-axis indicate significant subgroups revealed by post-hoc analysis of the MANOVA results for time spent active (Table 3). (B) Mean at each age (expressed as developmental age) for all 5 species (the 3 anemonefish species, Pomacentrus amboinensis and Sphaeramia nematoptera). Mean \pm SEs are based on the mean of 3 clutches at each age for the anemonefish larvae $(\mathrm{n}=3)$ and on individual fish for $P$. amboinensis and $S$. nematoptera ( $\mathrm{n}=9$ to 38 )

of nocturnal activity just before settlement (Fig. 4B). Nocturnal activity data are only available for 3 ages of Sphaeramia nematoptera, but again, this is consistent with early-stage larvae showing little activity at nighttime, which increases only for older larvae (Fig. 4B).

Paired $t$-tests indicated no significant difference in the undisturbed swimming speed of larvae at night between the early and late filming times (Table 2). Anemonefish larvae near settlement swim at much higher average and maximum speeds at night than they do during the day (Fig. 5). Average undisturbed swimming speed during the day for these 3 clutches was $2.7 \mathrm{~cm} \mathrm{~s}^{-1}$, whereas at night larvae swam at $6.2 \mathrm{~cm}$ $\mathrm{s}^{-1}$ (Fig. 5A). Maximum undisturbed swimming speeds during the day were considerably higher than the average daytime speeds $\left(6.4 \mathrm{~cm} \mathrm{~s}^{-1}\right)$, and at night the maximum undisturbed swimming speeds of larvae were as high as $14.2 \mathrm{~cm} \mathrm{~s}^{-1}$ (Fig. 5B). Average nighttime undisturbed swimming speeds of larvae are similar to their maximum daytime speeds (Fig. 5). 


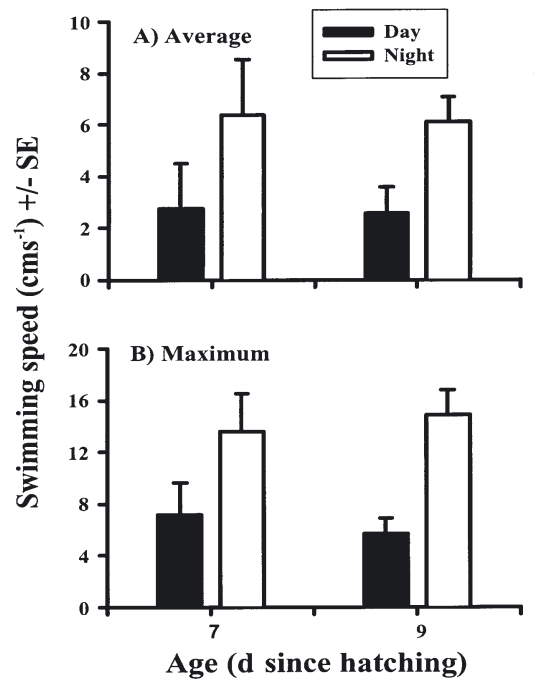

Fig. 5. (A) Average and (B) maximum undisturbed swimming speed both day and night, 7 and $9 \mathrm{~d}$ after hatching. Data are for 3 clutches of anemonefish larvae (1 clutch of Premnas biaculeatus and 2 clutches of Amphiprion melanopus). MANOVA found a significant effect for time of day (Pillai's trace $F_{2,7}=6.93, \mathrm{p}=0.022$ ) but no effect of age (Pillai's trace $\left.F_{2,7}=0.049, \mathrm{p}=0.95\right)$. There was no significant interaction (Pillai's trace $F_{2,7}=0.87, \mathrm{p}=0.46$ ). Both average and maximum undisturbed swimming speeds were significantly different between day and night (average $F_{1,8}=9.06, \mathrm{p}=0.017$; $\left.\max F_{1,8}=15.173, \mathrm{p}=0.005\right)$

\section{DISCUSSION}

\section{Diurnal undisturbed swimming speeds}

Although it is known that reef fish larvae can swim at high speeds in flumes (Fisher et al. 2000), we have found that the larvae of tropical reef fishes routinely swim at high relative speeds throughout their larval phase, even under undisturbed conditions. In this study, the average undisturbed swimming speeds of pomacentrid species range from 3.7 to $5.7 \mathrm{bl} \mathrm{s}^{-1}$, with maximum undisturbed swimming speeds up to $11.2 \mathrm{bl} \mathrm{s}^{-1}$. The results strongly support work based on maximal performance measures of swimming ability (Stobutzki \& Bellwood 1997, Fisher et al. 2000) and in situ field observations (Leis \& Carson-Ewart 1997), which indicate that these fishes are highly active, mobile organisms with considerable potential to control their position in the open ocean. The fact that the maximum passive speeds attained by larvae fall very close to $50 \%$ of their average U-crit values provides strong support for earlier hypotheses that larvae should be able to maintain such speeds for extended periods of time (Fisher \& Bellwood 2002). The average undisturbed speeds of larvae in the experiments were also quite high, with larvae maintaining speeds of ca. $20 \%$ of their U-crit.
The average undisturbed swimming speeds measured are in the range of routine-swimming speeds reported for subtropical red drum larvae Sciaenops ocellatus nearing settlement $\left(3.3 \mathrm{bl} \mathrm{s}^{-1}\right)$, but are much higher than values reported for younger larvae of this same species (0.5 bl s${ }^{-1}$; Fuiman et al. 1999). The results are also considerably greater than those reported in previous studies on temperate larvae, which recorded speeds of ca. $1 \mathrm{bl} \mathrm{s}^{-1}$ for larvae moving freely in tanks (Blaxter 1986). Maximum undisturbed swimming speeds of all species were 2 to 3 times faster than their average undisturbed swimming speeds (up to $11.2 \mathrm{bls}^{-1}$ in Pomacentrus amboinensis). Although these speeds are quite fast, we do not believe that they represent unsustainable burst swimming speeds for 2 reasons: firstly, the maximum daytime undisturbed swimming speeds of late-stage anemonefish larvae are similar to their average nocturnal undisturbed swimming speed, which appears to be sustained throughout the night (up to $11 \mathrm{~h}$ ). Secondly, the maximum undisturbed swimming speeds were, on average, much less than the U-crit for all species examined. U-crit provides a measurement of the maximum swimming speed of larvae (Brett 1964) that is considerably slower than burst speed. It is termed a 'sustained' speed, but the duration is highly variable and often covers only a relatively short time period. Fisher \& Bellwood (2002) show that the U-crit of the species examined is unlikely to be sustained for more than $10 \mathrm{~h}$.

It is possible that the concentration of food items and the density of larvae in the rearing tank may influence the swimming speeds of larvae. Changes in activity in response to food availability have been demonstrated for some species of larval fishes (Hecht et al. 1996, Kasumyan et al. 1998, Dou et al. 2000). However, we found no evidence that there was any difference in the swimming speeds of larvae measured early in the day (1 to $3 \mathrm{~h}$ after lights on) and later in the afternoon (1 to $3 \mathrm{~h}$ before lights off), suggesting that food concentration had little impact on undisturbed swimming speeds.

The slower undisturbed swimming speeds of Sphaeramia nematoptera larvae are consistent with the limited swimming capabilities exhibited by apogonids, both at settlement (Leis \& Carson-Ewart 1997, Stobutzki \& Bellwood 1997) and during development (Fisher et al. 2000), and appears to be a general characteristic of this family. Slower swimming speeds imply a lower foodencounter rate as well as decreased metabolic requirements, and suggest that larvae may adopt different energetic strategies depending on swimming speed (Hunter 1981). Similar differences in swimming speeds and feeding strategies have been observed among larvae of temperate species (MacKenzie \& Kiørboe 1995). The differences among taxa in swimming speeds have consequences for the behavioural mechanisms 
available to larvae for active self-recruitment. For example, deeper depth distributions (Leis 1991) coupled with superior visual capabilities in low light of apogonid larvae (Job \& Bellwood 2000) suggest that this group spends a significant amount of time in an environment with relatively slow current speeds, where swimming abilities will be of reduced importance. In comparison, pomacentrid larvae occur in shallower environments and, as such, their swimming abilities are likely to be of greater importance in influencing dispersal.

\section{Nocturnal behaviour}

Although there were clear differences among taxa in terms of undisturbed swimming speeds of larvae, all 5 species showed similar patterns of nocturnal swimming activity during development. In all species, the highest levels of nocturnal activity were recorded shortly before settlement. Low levels of nocturnal activity by reef fish larvae early in their pelagic phase are probably associated with an energy-saving strategy during the hours of darkness, when larvae are unable to feed (Hunter \& Sanchez 1976, Job \& Bellwood 2000). Although this study has only examined 2 families of reef fishes, these differ considerably in their diurnal behaviour and visual capabilities. Apogonids are nocturnal as adults, whereas pomacentrids are diurnal, and larval apogonids have a lower light threshold for feeding than pomacentrids of similar developmental age (Job \& Bellwood 2000). The close similarities in the ontogeny of nocturnal activity among these families suggest that this pattern of nocturnal activity may be similar for a range of reef fish taxa.

It is well known that older-stage reef fish larvae are active a night; this is when many species actively settle onto reefs (Dufour \& Galzin 1993, Holbrook \& Schmitt 1997). Our results suggest that this active nighttime behaviour only begins in the last few days before settlement. Furthermore, the faster undisturbed swimming speeds of larvae at night compared to during the day, near to settlement, suggest that the onset of active nocturnal behaviour is linked to active settlement behaviour of these larvae. It seems clear that larval behaviour changes considerably in the few days prior to settlement, providing additional evidence that settlement is an active, behaviourally mediated process.

\section{Measuring undisturbed swimming speeds}

This study used larvae reared in an enclosed environment to examine undisturbed swimming speeds and changes in nocturnal behaviour throughout development. It is difficult to establish how the behaviour of these larvae may differ from those in the field. It is possible that larvae nearing settlement may have reduced swimming activity relative to their 'normal' swimming speeds in the field because of the absence of external stimuli (such as chemical or auditory cues coming from suitable settlement sites). This may explain why 2 of the 3 species examined showed a decrease in undisturbed swimming speed relative to U-crit towards the end of the larval phase. Undisturbed swimming speeds of all larvae throughout development may also be reduced relative to field speeds, given that larvae are known to increase their feeding activity in the presence of turbulence (MacKenzie \& Kiørboe 1995), which was absent in our laboratory environment. This suggests that the undisturbed swimming speeds reported here are probably conservative, compared to what may be expected to occur in the field.

An alternative to the laboratory study presented here is the work of Leis \& Carson-Ewart (1997), which examines the swimming speeds of larvae in situ. The advantage of their method is that the behaviour of larvae can be examined in the presence of natural sensory cues, natural levels of turbulence and water flow, as well as with the full range of horizontal and vertical spatial scales. The problem with in situ measures of swimming speed, however, is that it is impossible to remove the effects of diver presence from observations of swimming speed and behaviour. In addition, such measurements can only be made for older-stage larvae that are large enough to be followed on SCUBA, and are further restricted to those species and stages that are available from light traps. At present, filming larvae in rearing aquaria is the only method available for measuring the undisturbed swimming speeds of larvae, particularly throughout development. Nevertheless the methods do offer complementary evidence. In situ measurement of the swimming speed for settlement stage larval Pomacentrus amboinensis has been reported as $11.8 \mathrm{~cm} \mathrm{~s}^{-1}$. This lies between the average $\left(7.6 \mathrm{~cm} \mathrm{~s}^{-1}\right)$ and maximum $\left(14.9 \mathrm{~cm} \mathrm{~s}^{-1}\right)$ undisturbed speeds recorded in our study. In addition, the relative swimming abilities of the different species examined in our study at settlement are similar to those reported in flume-based studies of larval abilities (Stobutzki \& Bellwood 1997). The close similarities among the different methods for measuring swimming ability of larvae near settlement suggest that larvae from rearing experiments may provide a good indication of the relative potential of these larvae during ontogeny.

\section{Implications of larval behaviour}

The speeds maintained during undisturbed swimming by reef fish larvae throughout development have 
important implications for the potential impact that their behaviour may have on dispersal patterns. Reef fish larvae are known to show positive rheotaxis throughout development (indeed this underpins all swimming measurements using flumes; see Fisher et al. 2000). If these larvae were to behave similarly in the field, or show other directed swimming behaviour (e.g. towards their natal reef), then even at the average undisturbed swimming speeds observed in this study, they have the potential to actively retain their position within the vicinity of their natal reef. Furthermore, current speeds decrease rapidly near the substratum. If larvae combine directed swimming behaviour with active vertical migration, avoiding faster current flows by dropping lower down in the water column (see Boehlert \& Mundy 1993, Armsworth 2001), they could potentially avoid advection from their natal reefs completely. Such a simple mechanism could largely account for recent suggestions of high levels of selfrecruitment of some tropical reef fish species (e.g. Jones et al. 1999, Swearer et al. 1999, see also Cowen et al. 2000).

Our results strongly suggest that such a mechanism of self-recruitment is well within the capabilities of the larvae of the species examined. Subsurface currents (after removal of tidal effects; as net transport is of interest here because this is the distance larvae must be able to swim to remain near their natal reef) within the Great Barrier Reef (GBR) lagoon in summer range from 5.6 to $15.6 \mathrm{~cm} \mathrm{~s}^{-1}$ in the northern section near Lizard Island (Andrews 1983, Frith et al. 1986). Because of boundary layer effects, net speeds may be much slower near the substratum. For example, in the Florida Keys, Pitts (1994) recorded speeds between 2.3 and $6.1 \mathrm{~cm} \mathrm{~s}^{-1}$ measured $4 \mathrm{~m}$ above the substratum vs 0.4 to $2.3 \mathrm{~cm} \mathrm{~s}^{-1} 2 \mathrm{~m}$ above the substratum. In comparison, the average undisturbed swimming speeds of Amphiprion melanopus larvae ranged from 1.7 to $2.9 \mathrm{~cm} \mathrm{~s}^{-1}$ from hatching to settlement (3.8 to $6.6 \mathrm{~cm} \mathrm{~s}^{-1}$ maximum) and larval Pomacentrus amboinensis swam between 1.5 and $7.6 \mathrm{~cm} \mathrm{~s}^{-1}$ (2.9 to $14.9 \mathrm{~cm} \mathrm{~s}^{-1}$ maximum). Even at hatching, these speeds could limit the impact of advecting currents, while at settlement, larvae could exceed prevailing current speeds (at least for short time periods).

Based on daytime undisturbed swimming speeds throughout development and nighttime speeds near settlement, conservative estimates indicate that $\mathrm{Am}$ phiprion melanopus and Pomacentrus amboinensis larvae would swim the equivalent of 13.1 to $30.4 \mathrm{~km}$ (calculations are based on average undisturbed speeds and $12 \mathrm{~h} \mathrm{~d}^{-1}$ in the early larval phase). Based on maximum speeds (that represent ca. $30 \%$ of the swimming time), the values would be 50.0 to $103.5 \mathrm{~km}$, respectively. In comparison, based on mid-water current speeds, Frith et al. (1986) estimated that larvae would be transported between 4 and $47 \mathrm{~km} \mathrm{wk}^{-1}$ during the summer spawning season at Lizard Island. These values suggest that the swimming speeds required for active self-recruitment by larvae are within the range observed for undisturbed swimming speeds of at least some reef fish species. These results are unique because they are based on swimming speeds that larvae maintain routinely throughout ontogeny. Contrary to recent suggestions by some authors (e.g. Mora \& Sale 2002), this swimming behaviour should incur no additional energetic penalty, nor increase the chance of detection by predators relative to what larvae would encounter due to normal day-to-day behaviour. Our study, for the first time, puts behaviour and swimming ability into an ecological and oceanographic context by describing undisturbed patterns of diurnal and nocturnal swimming throughout development.

Our paper has concentrated on several species of reef fish that all come from demersal eggs. The results show that an active mechanism for self-recruitment is within the behavioural capabilities of at least some species of reef fish larvae. This seems particularly true for the Amphiprioninae, which, given their precocial development, certainly have the behavioural abilities for an active mechanism of self-recruitment. This may largely account for the high degree of genetic differentiation apparent in this group (Bell et al. 1982). However, the behaviour of species with planktonic eggs may have less influence on dispersal compared to demersal spawning taxa because they tend to be smaller and less well developed at hatching, and have a longer pelagic larval phase (Thresher 1991). For species with pelagic eggs and longer larval durations, physical forces are likely to predominate in dispersal patterns over behaviour in the first few days after hatching. However, the much greater swimming abilities at settlement of many species with planktonic eggs and longer larval durations (e.g. Lethrinidae and Acanthuridae; Fisher \& Bellwood 2002) may counteract their slower rate of development. Consequently, they may have similar potential to utilise active behaviour to influence dispersal patterns, albeit later in the pelagic phase.

Although this study has shown that some species are capable of utilising active behaviour to facilitate retention on natal reefs, unfortunately there are no data on either rheotactic or homing behaviour of pelagic-stage reef fish larvae in the field. If orientation behaviour were initiated soon after hatching, and larvae were able to remain within the sensory zone of their natal reef, from the outset larvae would have the full array of sensory cues available to them for orientation (see Montgomery et al. 2001). Fish larvae have well-developed chemosensory capabilities, and there 
is a suite of potential chemical cues available on the leeward side of reefs (Atema et al. 2002). Furthermore, noise may provide larvae with a multidirectional navigational cue (Stobutzki \& Bellwood 1998, McCauley $\&$ Cato 2000, Tolimieri et al. 2000).

This study represents the first description of the undisturbed swimming speeds and nocturnal swimming activity of tropical reef fish larvae throughout development. The results demonstrate that larvae maintain relatively high swimming speeds throughout their larval phase, although differences in swimming speeds among taxa indicate that larvae may adopt different energetic strategies whilst in the pelagic environment. However, consistent patterns of nocturnal swimming behaviour among 5 species from 2 different families suggest that some behavioural characteristics may be similar for a range of reef fish taxa, and point to active nocturnal settlement behaviour. It is clear that some larval reef fishes are innately highly active, mobile organisms with considerable potential to control their position in the open ocean. Furthermore, they possess all the behavioural and functional attributes required for an active mechanism of self-recruitment on coral reefs. For some reef fish species, behaviour that enhances self-recruitment may be a central part of their normal behavioural repertoire.

Acknowledgements. This study was supported by a James Cook University Doctoral Merit Research Scheme, the CRC Reef Research Centre (RF), and the Australian Research Council (DRB). JCU experimentation ethics approval A202, 402. Particular thanks go to R. Beare from CSIRO Mathematical and Information Sciences, Sydney, Australia for supplying the tracking program 'Vedda' and substantial technical assistance. Thanks also to R. Scott, S. Delean, D. Firman, G. Carlos, T. Hancock, S. Conolly, A. Hoey and P. Munday for valuable advice and assistance; the staff of the James Cook University Research Aquarium, and C. Hoffman, K. Bott and L. Valentine for help with larval rearing; R. Rowe and J. Holtum for technical equipment; S. Wilson for advice throughout the project and valuable comments on the manuscript. Centre for Coral Reef Biodiversity publication \# 84.

\section{LITERATURE CITED}

Andrews JC (1983) Water masses, nutrient levels and seasonal drift on the outer central Queensland shelf (Great Barrier Reef). Aust J Mar Freshw Res 34:821-834

Armsworth PR (2001) Directed motion in the sea: efficient swimming over movement scales by reef fish larvae. J Theor Biol 210:81-91

Armsworth PR, James MK, Bode L (2001) When to press on or turn back: dispersal strategies for reef fish larvae. Am Nat 157:434-450

Atema J, Kingsford MJ, Gerlach G (2002) Larval reef fish could use odour for detection, retention and orientation to reefs. Mar Ecol Prog Ser 241:151-160

Batty RS (1987) Effect of light intensity on activity and foodsearching of larval herring, Clupea harengus: a laboratory study. Mar Biol 94:323-327
Bell L, Moyer J, Numachi K (1982) Morphological and genetic variation in Japanese populations of the anemonefish Amphiprion clarkii. Mar Biol 72:99-108

Bellwood DR, Leis JM, Stobutzki IC (1998) Fishery and reef management. Science 279:2021-2022

Blaxter JHS (1986) Development of sense organs and behaviour of Teleost larvae with special reference to feeding and predator avoidance. Trans Am Fish Soc 115:98-114

Boehlert G, Mundy B (1993) Ichthyoplankton assemblages at seamounts and oceanic islands. Bull Mar Sci 53:336-361

Brett JR (1964) The respiratory metabolism and swimming performance of young sockeye salmon. J Fish Res Board Can 21:1183-1226

Cowen RK (2002) Larval dispersal and retention and consequences for population connectivity. In: Sale P (ed) Coral reef fishes; diversity and dynamics in a complex ecosystem. Academic Press, San Diego, p 149-170

Cowen RK, Lwiza KMM, Sponaugle S, Paris CB, Olsen DB (2000) Connectivity of marine populations: open or closed? Science 287:857-859

Doherty PJ, Williams DMcB (1988) The replenishment of coral reef fish populations. Oceanogr Mar Biol Annu Rev 26: $487-551$

Doherty PJ, Planes S, Mather P (1995) Gene flow and larval duration in seven species of fish from the Great Barrier Reef. Ecology 76:2373-2391

Dou S, Sekai T, Tsukamoto K (2000) Feeding behaviour of Japanese flounder larvae under laboratory conditions. J Fish Biol 56:654-666

Dufour V, Galzin R (1993) Colonisation patterns of reef fish larvae to the lagoon at Moorea Island, French Polynesia. Mar Ecol Prog Ser 102:143-152

Fisher R, Bellwood DR (2001) Effects of feeding on the sustained swimming abilities of late-stage larval Amphiprion melanopus. Coral Reefs 20:151-154

Fisher R, Bellwood DR (2002) The influence of swimming speed on sustained swimming performance of late-stage reef fish larvae. Mar Biol 140:801-807

Fisher R, Bellwood DR, Job SD (2000) The development of swimming abilities in reef fish larvae. Mar Ecol Prog Ser 202:163-173

Frith CA, Leis JM, Goldman B (1986) Currents in the Lizard Island region of the great barrier reef lagoon and their relevance to potential movements of larvae. Coral Reefs 5:81-92

Fuiman LA, Poling KR, Higgs DM (1998) Quantifying developmental progress for comparative studies of larval fishes. Copeia 1998:602-611

Fuiman LA, Smith ME, Malley VN (1999) Ontogeny of routine swimming speed and startle responses in red drum, with a comparison of responses to acoustic and visual stimuli. J Fish Biol 55:215-226

Hecht T, Battaglene S, Talbot B (1996) Effect of larval density and food availability on the behaviour of pre-metamorphosis snapper, Pagrus auratus (Sparidae). Mar Freshw Res 47:223-231

Hindell JS, Jenkins GP, Moran SM, Keough MJ (2003) Swimming ability and behaviour of post-larvae of a temperate marine fish re-entrained in the pelagic environment. Oecologia 135:158-166

Holbrook SJ, Schmitt RJ (1997) Settlement patterns and process in a coral reef damselfish: in situ nocturnal observations using infra red video. Proc 8th Int Coral Reef Symp 2:1143-1148

Hunter JR (1972) Swimming and feeding behaviour of larval anchovy Engraulis mordax. Fish Bull 70:821-838

Hunter JR (1981) Feeding ecology and predation of marine 
fish larvae. In: Laker R (ed) Marine fish larvae. University of Washington, p 33-79

Hunter JR, Kimbrell CA (1980) Early life history of pacific mackerel, Scomber japonicus. Fish Bull 78:89

Hunter JR, Sanchez C (1976) Diel changes in swim bladder inflation of the larvae of the Northern anchovy, Engraulis mordax. Fish Bull 74:847

Job SD, Bellwood DR (2000) Light sensitivity in larval fishes: implications for vertical zonation in the pelagic zone. Limnol Oceanogr 45:362-371

Job SD, Shand J (2001) Spectral sensitivity, implications for feeding in a visually variable environment. Mar Ecol Prog Ser 214:267-277

Jones GP, Milicich MJ, Emslie MJ, Lunow C (1999) Self recruitment in a coral reef fish population. Nature 402: 802-804

Kasumyan A, Ryg M, Doving K (1998) Effect of amino acids on the swimming activity of newly hatched turbot larvae (Sophthalmus maximus). Mar Biol 131:189-194

Leis JM (1991) Vertical distribution of fish larvae in the Great Barrier Reef Lagoon, Australia. Mar Biol 109:157-166

Leis JM, Carson-Ewart B (1997) In situ swimming speeds of the late pelagic larvae of some Indo-Pacific coral reef fishes. Mar Ecol Prog Ser 159:165-174

Leis J, McCormick M (2002) The biology, behaviour, and ecology of the pelagic, larval stage of coral reef fishes. In: Sale P (ed) Coral reef fishes; diversity and dynamics in a complex ecosystem. Academic Press, San Diego, p 171-200

Levine JS, MacNichol EF (1982) Colour vision in fishes. Sci Am 246:108-117

MacKenzie BR, Kiørboe T (1995) Encounter rates and swimming behaviour of pause-travel and cruise larval fish predators in calm and turbulent laboratory environments. Limnol Oceanogr 40:1278-1289

McCauley RD, Cato DH (2000) Patterns of fish calling in a nearshore environment in the Great Barrier Reef. Phil Trans R Soc Lond B 355:1289-1293

Editorial responsibility: Charles Birkeland (Contributing Editor), Honolulu, Hawaii, USA
Montgomery JC, Tolimieri N, Haine OS (2001) Active habitat selection by pre-settlement reef fishes. Fish Fish Ser 2: 261-277

Mora C, Sale PF (2002) Are populations of coral reef fish open or closed? TREE 17:422-428

Pitts PA (1994) An investigation of near-bottom flow patterns along and across Hawk Channel, Florida Keys. Bull Mar Sci 54:610-620

Roberts CM (1997) Connectivity and management of Caribbean coral reefs. Science 278:1454-1457

Roberts CM (1998) Fishery and reef management. Science 279:2022-2023

Shanks AL, Grantham BA, Carr MH (2003) Propagule dispersal distance and the size and spacing of marine reserves. Ecol Appl 13:5159-5169

Sponaugle S, Cowen RK, Shanks A, Morgan SG and 7 others (2002) Predicting self-recruitment in marine populations: biophysical correlates and mechanisms. Bull Mar Sci 70: 341-375

Stobutzki IC, Bellwood DR (1997) Sustained swimming abilities of the late pelagic stages of coral reef fishes. Mar Ecol Prog Ser 149:35-41

Stobutzki IC, Bellwood DR (1998) Nocturnal orientation to reefs by late pelagic stage coral reef fishes. Coral Reefs 17: 103-110

Swearer SE, Caselle JE, Lea DW, Warner RR (1999) Larval retention and recruitment in an island population of a coral-reef fish. Nature 402:799-802

Thresher RE (1991) Geographic variability in the ecology of coral reef fishes: evidence, evolution and possible implications. In: Sale P (ed) The ecology of fishes on coral reefs. Academic Press, San Diego, p 401-435

Tolimieri N, Jeffs A, Montgomery JC (2000) Ambient sound as a cue for navigation by the pelagic larvae of reef fishes. Mar Ecol Prog Ser 207:219-224

Trnski T (2002) Behaviour in settlement-stage larvae of fishes with an estuarine juvenile phase: in situ observations in a warm-temperate estuary. Mar Ecol Prog Ser 242:205-214

Submitted: October 1, 2002; Accepted: August 28, 2003

Proofs received from author(s): November 3, 2003 